\title{
Supporting Awareness of Others in Groupware
}

\author{
Carl Gutwin, Saul Greenberg, and Mark Roseman \\ Department of Computer Science, University of Calgary \\ Calgary Canada T2N $1 \mathrm{~N} 4$ \\ Tel: +1 403 220-6015 \\ E-mail: [gutwin, saul, roseman]@cpsc.ucalgary.ca
}

\section{INTRODUCTION}

Successful collaboration in a work community requires that members of the group maintain awareness of one another on several levels. The following papers consider kinds of awareness and how these can be supported in groupware systems. In particular, the papers explore two kinds of awareness: first, general awareness of people in a work community, and second, awareness of others' interactions with a shared workspace.

In everyday work, informal awareness involves knowing who's currently around, whether they're available or busy, and what sort of activity they're engaged in. People need informal awareness in order to find opportunities for collaboration and people to collaborate with [1]. Once they have begun a collaborative activity using a shared workspace (such as a whiteboard or a document), they then need to maintain workspace awareness: where in the space others are working, what they are doing, and what changes they are making [2].

These same needs also exist when people work together through groupware. However, the cues and mechanisms that help people maintain awareness of others in face-toface activity are often difficult to provide in groupware systems. For example, a virtual community becomes invisible on the network, and it is hard to see who is available for interaction. Also, glancing over at another part of a workspace to monitor another person's activities does not translate well to a groupware environment, especially if relaxed-WYSIWIS view sharing is in effect.

$\mathrm{CSCW}$ research has considered some of the issues surrounding awareness in cooperative work: general awareness of a work community has been supported through media spaces, and certain elements of awareness within a workspace have been supported with specialized displays in groupware systems. The papers in this suite build on these results and explore various facets of how awareness of others can be supported in groupware

Permission to make digital/hard copies of all or part of this material for personal or classroom use is granted without fee provided that the copies are not made or distributed for profit or commercial advantage, the copyright notice, the title of the publication and its date appear, and notice is given that copyright is by permission of the ACM, Inc. To copy otherwise, to republish, to post on servers or to redistribute to lists, requires specific permission and/or fee.

CHI ' 96 Companion, Vancouver, BC Canada

- 1996 ACM 0-89791-832-0/96/04..\$3.50 systems. Together, the papers cover theoretical considerations, practical efforts in building systems and widgets to support awareness, and evaluation of widgets to determine their effectiveness and usability.

The first paper concerns informal awareness, and describes a system that provides information about people's whereabouts and activities, without requiring video connections. The second paper looks at awareness requirements of collaborative interaction in a shared workspace. It describes workspace awareness and organizes several elements into a conceptual framework that can be used as the basis for building groupware support.

The next two papers describe inventions that have been built as experimental supports for workspace awareness. The first of these presents a class of widgets called radar views, and the second discusses how fisheye visualization techniques can be used as a basis for providing awareness information in groupware.

The final paper reports on a study carried out to evaluate the usability and effectiveness of several awareness widgets in a realistic groupware application. The study reinforces the idea that workspace awareness is maintained and used in collaborative activity, and found that some widget designs were successful in providing some of the awareness information that participants needed.

The experiences gathered within these papers argue that awareness issues must be considered more generally in the design of groupware systems. In addition, further exploration of how awareness works can help groupware systems better support the natural, facile interactions that mark everyday face-to-face collaboration.

More information about the research discussed in these papers can be found at the GroupLab web site: http://www.cpsc.ucalgary.ca/projects/grouplab/

\section{REFERENCES}

1. Kraut, R., Egido, C., and Galegher, J. Patterns of Contact and Communication in Scientific Research Collaborations. In Intellectual Teamwork. J. Galegher, R. Kraut, and C. Egido eds. LEA Press, 1990, 149-172.

2. Gutwin, C., Stark, G., and Greenberg, S. Supporting Workspace Awareness in Educational Groupware. In Proc. CSCL'95, Bloomington, IN, (1995), pp. 147-156. 